\title{
Bicuspid aortic valve aortopathy: One size fits all?
}

\author{
Hans-Joachim Schäfers, MD
}

\footnotetext{
From the Department of Thoracic and Cardiovascular Surgery, Saarland University Medical Center, Homburg/ Saar, Germany.

Disclosures: Author has nothing to disclose with regard to commercial support.

Received for publication June 17, 2018; revisions received June 17, 2018; accepted for publication June 18, 2018; available ahead of print Aug 7, 2018.

Address for reprints: Hans-Joachim Schäfers, MD, Department of Thoracic and Cardiovascular Surgery, Saarland University Medical Center, Homburg/Saar, Germany (E-mail: h-j.schaefers@uks.eu).

J Thorac Cardiovasc Surg 2019;157:526-7

$0022-5223 / \$ 36.00$

Copyright $(\underset{2018}{ } 20 \mathrm{by}$ The American Association for Thoracic Surgery

https://doi.org/10.1016/j.jtcvs.2018.06.052
}

It well documented that a relevant proportion of patients with a bicuspid aortic valve (BAV) will have development of aneurysmal dilatation of the ascending aorta. ${ }^{1}$ It is increasingly recognized that this aortopathy not only varies in its extent or phenotype ${ }^{2}$ but also includes a spectrum of clinical scenarios, including different forms of aortic valve dysfunction.

Older guidelines recommended an aortic diameter threshold of $5 \mathrm{~cm}$ as trigger for surgical therapy in patients with BAV. ${ }^{3}$ In the past 10 years, it has become more apparent that the risk of aortic dissection is actually lower than previously thought for the majority of patients with $\mathrm{BAV},{ }^{4}$ and guidelines have consequently been modified. The threshold for surgery has been increased to $5.5 \mathrm{~cm}$, and only in the presence of risk factors is the previous threshold of $5 \mathrm{~cm}$ maintained. ${ }^{5}$

Nonetheless, actual clinical decision making has not always followed current guidelines, ${ }^{6}$ and it is worth reconsidering the background of the guidelines to improve counseling of patients and surgical decision making. In this context, the review by Braverman ${ }^{7}$ in this issue of the Journal provides valuable information that should be read and considered carefully.

Braverman $^{7}$ points out that the prognosis of aortic aneurysm in the presence of a BAV is not uniformly good. In fact, young patients with a root aneurysm of $5 \mathrm{~cm}$ are at an increased risk for development of dissection or for size increase of the aneurysm in the first 10 years after diagnosis. Equally important is the type of aortic valve dysfunction, with aortic regurgitation exposing the patient to a significantly higher chance of progressive dilatation than that seen with aortic stenosis.

As common sense indicates, patient size should also be considered, even though indexing aortic size to body surface area has not yet found entry into guidelines. Although $z$ scores are accepted criteria in pediatric cardiac surgery, the adult cardiology and cardiac surgery fields have been reluctant to use them in the context of aneurysm, an omission that should be reconsidered. Finally, age and comorbidity of the patient must be taken into consideration,

\section{References} 2008; 117:2776-84.

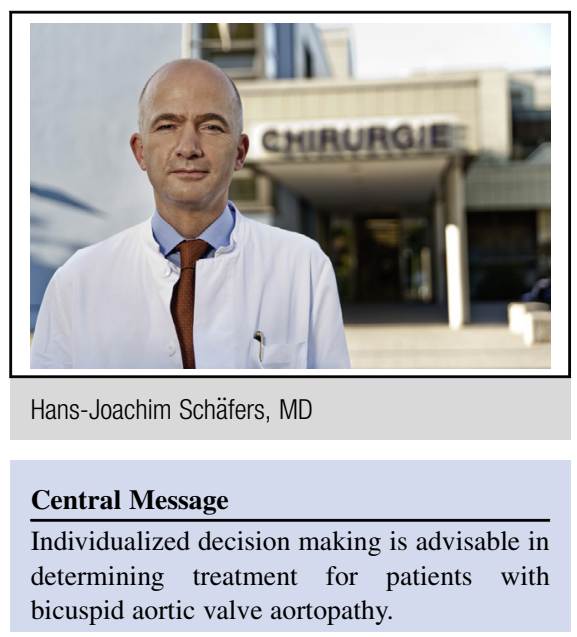

See Article page 520 .

because they have an effect on life expectancy as well as on the morbidity and mortality of the operation. ${ }^{8}$ The extent of surgery should be carefully planned. Aneurysm of the tubular aorta does not necessarily warrant aggressive root replacement, because in the vast majority of patients, the root will remain stable for a long time.'

The key message that treatment should be carefully considered on an individual basis is thus a very important one. Although an aortic diameter of more than $5.5 \mathrm{~cm}$ clearly triggers surgery adequately in many cases (always considering the anticipated risk of the procedure related to the patient's risk profile and experience of the surgeon), patients with lower aortic diameters should not automatically be followed up with observation alone but rather should be evaluated on an individualized basis. A high probability of valve preservation at the time of surgery may play an additional role in this process. ${ }^{10}$

1. Michelena HI, Desjardins VA, Avierinos JF, Russo A, Nkomo VT, Sundt TM, et al. Natural history of asymptomatic patients with normally functioning or minimally dysfunctional bicuspid aortic valve in the community. Circulation.

2. Verma S, Siu SC. Aortic dilatation in patients with bicuspid aortic valve. $N$ Engl J Med. 2014;370:1920-9.

3. American College of Cardiology/American Heart Association Task Force on Practice Guidelines, Society of Cardiovascular Anesthesiologists, Society for Cardiovascular Angiography and Interventions, Society of Thoracic Surgeons, Bonow RO, Carabello BA, et al. ACC/AHA 2006 guidelines for the management of patients with valvular heart disease: a report of the American College of Cardiology/American Heart Association task force on practice guidelines (writing committee to revise the 1998 guidelines for the management of patients with valvular heart disease): developed in collaboration with the Society of Cardiovascular Anesthesiologists: endorsed by the Society for Cardiovascular Angiography and Interventions and the Society of Thoracic Surgeons. Circulation. 2006;114:e84-231. 
4. Michelena HI, Khanna AD, Mahoney D, Margaryan E, Topilsky Y, Suri RM, et al. Incidence of aortic complications in patients with bicuspid aortic valves. JAMA. 2011;306:1104-12.

5. Nishimura RA, Otto CM, Bonow RO, Carabello BA, Erwin JP III, Guyton RA, et al; American College of Cardiology; American College of Cardiology/American Heart Association; American Heart Association. 2014 AHA/ACC guideline for the management of patients with valvular heart disease: a report of the American College of Cardiology/American Heart Association task force on practice guidelines. J Thorac Cardiovasc Surg. 2014;148:e1-132. Erratum in: J Thorac Cardiovasc Surg. 2014;64: 1763.

6. Verma S, Yanagawa B, Kalra S, Ruel M, Peterson MD, Yamashita MH, et al. Knowledge, attitudes, and practice patterns in surgical management of bicuspid aortopathy: a survey of 100 cardiac surgeons. J Thorac Cardiovasc Surg. 2013 146:1033-40.e4.

7. Braverman AC. Aortic replacement for bicuspid aortic valve aortopathy: when and why? J Thorac Cardiovasc Surg. 2019;157:520-5.

8. Kunihara T, Aicher D, Asano M, Takahashi H, Heimann D, Sata F, et al. Risk factors for prophylactic proximal aortic replacement in the current era. Clin Res Cardiol. 2014;103:431-40.

9. Park CB, Greason KL, Suri RM, Michelena HI, Schaff HV, Sundt TM III. Fate of nonreplaced sinuses of Valsalva in bicuspid aortic valve disease. J Thorac Cardiovasc Surg. 2011;142:278-84.

10. Aicher D, Fries R, Rodionycheva S, Schmidt K, Langer F, Schäfers HJ. Aortic valve repair leads to a low incidence of valve-related complications. Eur J Cardiothorac Surg. 2010;37:127-32. 